\title{
COMPARISON OF DOCUMENTED PATIENT CARE BEFORE AND AFTER IMPLEMENTATION OF END OF LIFE CARE PATHWAY FOR TERMINALLY ILL PATIENTS AT SHAUKAT KHANUM MEMORIAL CANCER HOSPITAL AND RESEARCH CENTRE
}

Irum Ghafoor, Haroon Hafeez, Muhammad Abu Bakar, Farhat Naz

Department of Internal Medicine, Shaukat Khanum Memorial Cancer Hospital and Research Centre, Lahore, Pakistan

Received: 20 August 2018 / Accepted: 17 September 2018

Materials and Methods: We used a retrospective method to audit 45 terminally ill patients over a period of 3 months. Then, a re-audit was done over a period of 3 months and data were collected for patients who were started on SKMELC pathway.

Results: Results show that the implementation of ELC pathway, $67 \%$ of the patients were not prescribed PRN medications for symptom control, $20 \%$ of the patients were not reviewed for the need of assisted nutrition and for $20 \%$ of the patient's primary team were not even notified that the patient is dying. After the ELC pathway implementation, it was found that $100 \%$ of patients were reviewed for PRN medications and assisted nutrition. Oncologists were timely notified that the patient is dying.

Conclusion: In summary, we can say that implantation of ELC pathway has significantly improved documented patients care in all aspects.

Key words: Cancer, care for dying, end of life care, goals of care pathway

\section{Introduction}

Palliative care in managing patient with life-limiting illnesses has been recognised as an important aspect in the trajectory of cancer treatment and symptoms management. ${ }^{[1]}$ The American Cancer Society defines palliative care as supportive care provided to the individuals, who are diagnosed with incurable disease to relieve suffering and improve quality of life. The concept of modern palliative care started somewhere in 1960s with the emergence of modern hospice movement. ${ }^{[2]}$

Correspondence: Dr. Irum Ghafoor, Department of Internal Medicine, Shaukat Khanum Memorial Cancer Hospital and Research Centre, Lahore, Pakistan.

Email: irum.ghafoor@gmail.com
This movement was initiated by Cicely Saunders who is widely considered the founder of modern hospice care, and it was because of her instrumental efforts, End of life care (ELC) Services were incorporated in the hospital settings. ${ }^{[2]}$ In the western world, a lot of work and research has been done in this field to recognize the unique needs of dying patients and ways to address those needs. Worldwide, numerous palliative and hospice centres have been established. ${ }^{[3]}$ Unfortunately, in our country, these services are still in the developing phases and not much work has been done. ${ }^{[4]}$ This has led to a major knowledge gap in symptoms assessment, ELC planning and open communication with the patient about death and dying process. Since its inception, palliative care services are facing different kind of challenges and 
one of the major issues is creating separate palliative care unit with integrated end of life pathway. Except few, none of the tertiary care hospitals in Pakistan have structured guidelines, ${ }^{[5]}$ and pathways which can help the palliative care professional to address the unique needs of patients during the dying process. This lack of good clinical tools is a major reason behind infective multidisciplinary care and inadequate symptom management during the end of life period.

When patients are referred to palliative care services, less intensive but more integrated multidisciplinary approach is required to cater patient's holistic needs to improve the quality of life. ${ }^{[6]}$ Frequent transition in care plan is common among palliative care patients due to their complex clinical condition during the last days of life. ${ }^{[6]}$ These frequent fragmented care transitions can be stressful to both patients and their family members in many ways, which requires comprehensive clinical assessment and intervention. To address these needs, care pathways are developed. Care pathways are evidence-based set of guidelines which aim to address the needs of a specific group of population. ${ }^{[7]}$ These are the useful tools to identify a specific course of event in patient's care thus assisting in efficient and effective care delivery. ${ }^{[8]}$

Many such pathways have been developed to address the needs of patients who are confronted with the reality of death. Among them, the one which is widely used is Liverpool Care Pathway (LCP) for dying patients. ${ }^{[7]}$ The LCP for the dying patient is a multi-professional document that provides a template for client centered best practice and facilitates appropriate standards of record keeping. ${ }^{[7]}$ This pathway provides an algorithm to the palliative care professional to address the specific needs of the individuals when death is expected.

Shaukat Khanum Memorial-ELC pathway (SKMELC) has been devised from LCP for dying patients with international collaboration based at University of Liverpool. Before the implementation of this pathway, ELC to the dying patients was provided in a fragmented manner which resulted in ineffective documentation and reassessment of care. Thus, the purpose of this study was to audit the documented care of the patients before and after the implantation of this SKM ELC pathway to see the difference in care.

\section{Materials and Methods}

A descriptive audit was done in Palliative Care Department of Shaukat Khanum Memorial Cancer Hospital and Research Centre, Lahore, Pakistan. Both pre-implementation and post-implementation data were collected retrospectively from HIS.

All cancer patients at SKM Cancer Hospital and Research Cancer who were admitted due to terminal illness and then died within 3 months from $1^{\text {st }}$ March, 2017 to $31^{\text {st }}$ May, 2017 were included in the study. A total of 45 patients were admitted and selected for pre-implementation audit during the above-mentioned time period. Furthermore, for post-implementation, 32 patients were included over a period of 3 months from $1^{\text {st }}$ June, 2017 to $31^{\text {st }}$ August, 2017. Hospital information system was used to collect data of patients for pre pathway implementation audit. In addition, SKM-ELC pathway was used to collect the data from patients for post-implementation results. Consent was not required as data were reviewed retrospectively from the patient's medical record present in HIS at the time of audit. All terminally ill patients were included in both pre- and post-implementation audit, and retrospective study was done during these audits.

\section{Introduction to the SKM-ELC pathway}

There are three sections of this pathway:

1. Initial assessment and care

2. On-going assessment of the plan of care

3. Care after death.

Section 1: This section is jointly completed by palliative care physician and nurse. It consists of specific goals pertaining to the need of dying patients which assist in providing multidisciplinary holistic care to the patient and their family members. Followings are the goals which are part of this section.

\section{Goal no: 1: Communication}

- Goal 1.1: The patient is able to take a full and active part in communication.

- Goal 1.2: The relative or carer is able to take a full and active part in communication

- Goal 1.3: The patient is aware that they are dying Goal 1.4: The relative or carer is aware that the patient is dying, 


\section{Goal no: 2: Facilities}

- Goal 2.1: The relative or carer has had a full explanation of the facilities available to them.

\section{Goal no: 3: Spirituality}

- Goal 3.1: The patient is given the opportunity to discuss what is important to them at this time, for example, their wishes, feelings, faith, beliefs and values.

\section{Goal no: 4: Medications}

- Goal 4.1: The patient has medication prescribed on a PRN basis for all the specific symptoms which may develop in the last hours or days of life. Symptoms include pain, agitation, respiratory tract secretion, nausea/vomiting and dyspnoea.

- Goal 4.2: Equipment is available for the patient to support a continuous subcutaneous infusion of medication where required.

\section{Goal no: 5: Current interventions}

- Goal 5.1: The patient's need for current interventions has been reviewed by the multidisciplinary team (MDT).

- Goal 5.2: The patient has a do not attempt cardiopulmonary resuscitation order in place.

\section{Goal no: 6: Nutrition}

- Goal 6: The need for clinically assisted (artificial) nutrition is reviewed by the MDT.

\section{Goal no: 7: Hydration}

- Goal 7: The need for clinically assisted (artificial) hydration is reviewed by the MDT.

\section{Goal no: 8: Skincare}

- Goal 8: The patient's skin integrity is assessed.

\section{Goal no: 9: Explanation of the plan of care}

- Goal 9.1: A full explanation of the current plan of care is given to the patient/relative or carer.

- Goal 9.2: The SKM-ELC plan coping with dying leaflet or equivalent is given to the relative or carer.
Section-2: This section contains ongoing assessment and plan of care as per the patient's symptoms mention in the ELC pathway as shown in Appendix A 1.0.

Section-3: This includes care which is provided to the patient and their bereaved family. Following goal is the part of Section-3

\section{Goal no: 10: Care after death}

- Goal 10: Last offices are undertaken according to policy and procedure.

\section{Inclusion/exclusion criteria}

All the patients who were terminally ill during the period of data collection were included in the study and their documented care was reviewed. None of the patients improved during that time, so no one was excluded from the study. There was no patient loss during the data collection.

\section{Statistical analysis}

The data were collected by the team conducting the audit and analysed using IBM SPSS Statistics 20. All categorical variables were presented in frequencies and percentages.

\section{Results}

\section{Section-1: Initial assessment and care}

As mentioned above, a total of 45 patients were included in pre-implementation audit. When the results were analysed, there was a significant lack of documentation in communication with patients and their family members about impending death and their involvement in decisionmaking process. To our surprise, none of the patient's document revealed that patient and families spiritual needs were assessed and addressed at the end of life period. In all $100 \%$ of patients, multidisciplinary review of current interventions and plan of care was not documented. After implementation of SKM-ELC pathway, there was a significant improvement in documented care for dying patients. Almost all the goals mentioned in the pathway were assessed, and according to the need of the individuals, such needs were addressed. The details and comparison between the level of documentation in 
pre- and post-pathway implementation are mentioned in Table 1.

\section{Section-2 and 3 (on-going assessment of the plan of care and care after death)}

It includes ongoing assessment of plan of care by doing 4 hourly symptoms assessment including symptoms of pain, agitation, respiratory tract secretions, nausea, vomiting, breathless, and urinary and bowel problems, mouth cleaning, hydration, skin integrity, personal hygiene needs and psychological well-being of patient. This section also showed marked improvements in post audit results. Rest of the results of Section 2 and 3 is reported in Table 2.

This care after death that is missing in $6 \%$ of patients after the implementation of this pathway is because of the fact that the family wanted to take patients home during their terminal condition. So for their best interest, patients were discharged as requested after home arrangements were made.

After implementation of SKM-ELC pathway, it was noticed that there was a significant improvement in the documented care of the patient with regard to certain goals as indicated below.

\section{Discussion}

A clinical pathway is the systematic approach to cater to the holistic needs of dying patients and study shows that implementation of such pathways can enhance the therapeutic relationship with the patients and their family members. ${ }^{[8-11]}$ Our study also indicated that after the implementation of the ELC pathway there was a significant change in the management of patient's symptoms. This included significant improvement in pain management, discussion about the dying process, 4 hourly symptoms assessment and creating open platform for the patient and their families to discuss their concerns. The time around death is a complex process, and research shows that uncertainties are common when the death is approaching. ${ }^{[12]}$

The complex nature of this situation makes it reality difficult for the palliative care professionals to adequately address individual's needs. ${ }^{[12]}$ Our study also showed a significant lack of documentation about the care provided to the individuals and we are not sure whether those needs were addressed or not. However, implementation of care pathway made a significant impact to make things easier for health-care professional to assess and address patient's complex needs during the end of life period. It's evident from our results that there was marked improvement in documentation of how patient's physical, psychological, spiritual needs were addressed.

The truth cannot be denied that the implementation of palliative pathway does not postpone death because death is inevitable in certain disease conditions. However, 100\% documented care compliance provides enough evidence that the care which was being given to these patients was holistic in manner. Introduction of this pathway definitely improved patient's management in terms of systematic care delivery. This shows that patients were being managed in all aspect.

Overall changes in care of the dying patient have been observed after the introduction of the SKM-ELC pathway. Anecdotally, hospital staff and relatives report that care of the dying patient has improved when care was provided using an appropriate tool and pathway. ${ }^{[13]}$ However, challenges still exist in our country when it comes to strengthen palliative care services. ${ }^{[14]}$ Basic palliative care is available in the private sector only in SKM Cancer Hospital, Lahore, Aga Khan University Hospital (AKUH), Karachi, Children's Cancer Hospital, Karachi and a few Christian hospices in Karachi, Hyderabad and Rawalpindi. ${ }^{[5]}$ Only Shaukat Khanum Cancer hospital has separate palliative care unit. The AKUH has an established home health service that arranges physicians, nurses, physiotherapists and phlebotomists to visit patients' homes and provide the care required. Formal home-based services are not available elsewhere. The lack of formal home-based services necessitates repeated visits to the hospital by patients in need of palliative care and results in death in hospitals. ${ }^{[5]}$ Considering this situation it has become a necessity to bring transformational changes in the field of palliative services especially when it comes to help the patient experience good death. ${ }^{[15-17]}$ Our study showed that by introducing ELC pathway we have achieved one of the milestones in bringing transformative change in the field of palliative care.

Improving the documentation, by implementing the SKM-ELC pathway ensured that standardised care was 
Table 1: Comparison of section 1 pre- and post-implementation of end of life care pathway

\begin{tabular}{|c|c|c|c|}
\hline \multicolumn{4}{|l|}{ Section-1 } \\
\hline Variables & Characteristics & Pre-implementation, $n(\%)$ & Post-implementation, $n$ (\%) \\
\hline \multirow[t]{3}{*}{ Goal 1.1} & No & $0(0.0)$ & $30(94.0)$ \\
\hline & Yes & $18(40.0)$ & $2(6.0)$ \\
\hline & Not documented & $27(60.0)$ & $0(0.0)$ \\
\hline \multirow[t]{3}{*}{ Goal 1.2} & No & $0(0.0)$ & $0(0.0)$ \\
\hline & Yes & $45(100.0)$ & $32(100.0)$ \\
\hline & Not documented & $0(0.0)$ & $0(0.0)$ \\
\hline \multirow[t]{3}{*}{ Goal 1.3} & No & $15(33.0)$ & $29(91.0)$ \\
\hline & Yes & $30(67.0)$ & $3(9.0)$ \\
\hline & Not documented & $0(0.0)$ & $0(0.0)$ \\
\hline \multirow{3}{*}{ Goal 1.4} & No & $0(0.0)$ & $0(0.0)$ \\
\hline & Yes & $12(27)$ & $32(100.0)$ \\
\hline & Not documented & $33(73)$ & $0(0.0)$ \\
\hline \multirow[t]{3}{*}{ Goal 2.0} & No & $0(0.0)$ & $0(0.0)$ \\
\hline & Yes & $42(93.0)$ & $32(100.0)$ \\
\hline & Not documented & $3(7.0)$ & $0(0.0)$ \\
\hline \multirow[t]{3}{*}{ Goal 3.1} & No & $0(0.0)$ & $0(0.0)$ \\
\hline & Yes & $0(0.0)$ & $32(100.0)$ \\
\hline & Not documented & $45(100.0)$ & $0(0.0)$ \\
\hline \multirow[t]{3}{*}{ Goal 4.1} & No & $0(0.0)$ & $0(0.0)$ \\
\hline & Yes & $15(33.0)$ & $32(100.0)$ \\
\hline & Not documented & $30(67.0)$ & $0(0.0)$ \\
\hline \multirow{3}{*}{ Goal 4.2} & No & $30(67.0)$ & $0(0.0)$ \\
\hline & Yes & $15(33.0)$ & $32(100.0)$ \\
\hline & Not documented & $0(0.0)$ & $0(0.0)$ \\
\hline \multirow[t]{3}{*}{ Goal 5.1} & No & $0(0.0)$ & $0(0.0)$ \\
\hline & Yes & $0(0.0)$ & $32(100.0)$ \\
\hline & Not documented & $45(100.0)$ & $0(0.0)$ \\
\hline \multirow[t]{3}{*}{ Goal 5.2} & No & $0(0.0)$ & $0(0.0)$ \\
\hline & Yes & $45(100.0)$ & $32(100.0)$ \\
\hline & Not documented & $0(0.0)$ & $0(0.0)$ \\
\hline \multirow[t]{3}{*}{ Goal 6.0} & No & $0(0.0)$ & $0(0.0)$ \\
\hline & Yes & $36(80.0)$ & $32(100.0)$ \\
\hline & Not documented & $9(20.0)$ & $0(0.0)$ \\
\hline \multirow[t]{3}{*}{ Goal 7.0} & No & $0(0.0)$ & $0(0.0)$ \\
\hline & Yes & $45(100.0)$ & $32(100.0)$ \\
\hline & Not documented & $0(0.0)$ & $0(0.0)$ \\
\hline \multirow[t]{3}{*}{ Goal 8.0} & No & $0(0.0)$ & $0(0.0)$ \\
\hline & Yes & $45(100.0)$ & $32(100.0)$ \\
\hline & Not documented & $0(0.0)$ & $0(0.0)$ \\
\hline \multirow[t]{3}{*}{ Goal 9.1} & No & $0(0.0)$ & $0(0.0)$ \\
\hline & Yes & $0(0.0)$ & $32(100.0)$ \\
\hline & Not documented & $45(100.0)$ & $0(0.0)$ \\
\hline
\end{tabular}


Table 1: (Continued)

\begin{tabular}{l|l|c|c}
\hline Section-1 & \multicolumn{3}{|c}{} \\
\hline Variables & Characteristics & Pre-implementation, $\boldsymbol{n}(\%)$ & Post-implementation, $\boldsymbol{n}$ (\%) \\
\hline \multirow{3}{*}{ Goal 9.2 } & No & $0(0.0)$ & $0(0.0)$ \\
\cline { 2 - 4 } & Yes & $36(80.0)$ & $32(100.0)$ \\
\cline { 2 - 4 } & Not documented & $9(20.0)$ & $0(0.0)$ \\
\hline
\end{tabular}

Table 2: Comparison of section 2 and section 3 pre- and post-implementation of end of life care pathway

\begin{tabular}{|c|c|c|c|}
\hline Variables & Characteristics & Pre-implementation, $n(\%)$ & Post-implementation, $n(\%)$ \\
\hline \multicolumn{4}{|c|}{ Ongoing assessment of the plan of care } \\
\hline \multirow[t]{3}{*}{ Section-2 } & No & $0(0.0)$ & $0(0.0)$ \\
\hline & Yes & $12(27.0)$ & $32(100.0)$ \\
\hline & Not documented & $33(73.0)$ & $0(0.0)$ \\
\hline \multicolumn{4}{|c|}{ Care after death } \\
\hline \multirow[t]{3}{*}{ Section-3 } & No & $0(0.0)$ & $2(6.0)$ \\
\hline & Yes & $45(100.0)$ & $30(94.0)$ \\
\hline & Not documented & $0(0.0)$ & $0(0.0)$ \\
\hline
\end{tabular}

provided to the patients. This was helpful to minimize the chances of the level of care being missed. With this audit, we conclude that further palliative care education of all healthcare professionals is needed. There is increased interest about palliative care among patients and their relatives. ${ }^{[18-20]}$

\section{Conclusion}

Increased acknowledgement of the benefits of palliative care is required. This can be achieved by the integration of palliative care in the routine practice of oncology and other disease condition where palliative care remains the only option for better patient care. There is room for improvement when it comes to well-timed transfer of patients to palliative care that will likely to improve the patient care, and it will help in providing maximal ELC required for the dying patient.

\section{Limitation and future direction}

The limitation of our study was that it was done on a relatively small patient group and targeted only the inpatient population suffering from cancer. For future studies, we have made considerations to include all patients who do not have progressive cancer but due to comorbidities are considered for best supportive palliative care only.

\section{Conflict of Interest}

The authors declare that they have no conflict of interest.

\section{References}

1. Ghandourh WA. Palliative care in cancer: Managing patients' expectations. J Med Radiat Sci 2016;63:242-57.

2. Hui D, Bruera E. Integrating palliative care into the trajectory of cancer care. Nat Rev Clin Oncol 2016;13:159-71.

3. Milicevic N. The hospice movement: History and current worldwide situation. Arch Onco 2002;10:29-31.

4. Yusuf A. Cancer care in Pakistan. Jpn J Clin Oncol 2013;43:771-5.

5. Khan RI. Palliative care in Pakistan. Indian J Med Ethics 2017;2:37-43.

6. Casotto V, Rolfini M, Ferroni E, et al. End-of-life place of care, health care settings, and health care transitions among cancer patients: Impact of an integrated cancer palliative care plan. J Pain Symptom Manage 2017;54:167-75.

7. Costantini M, Ottonelli S, Canavacci L, et al. The effectiveness of the liverpool care pathway in improving end of life care for dying cancer patients in hospital. A cluster randomised trial. BMC Health Serv Res 2011;11:13.

8. Bookbinder M, Blank AE, Arney E, et al. Improving end-oflife care: Development and pilot-test of a clinical pathway. J Pain Symptom Manage 2005;29:529-43.

9. Main J, Whittle C, Treml J, et al. The development of an integrated care pathway for all patients with advanced lifelimiting illness - the supportive care pathway. J Nurs Manag 2006;14:521-8. 
10. Mirando S, Davies PD, Lipp A. Introducing an integrated care pathway for the last days of life. Palliat Med 2005;19:33-9.

11. Hardy JR, Haberecht J, Maresco-Pennisi D, et al. Audit of the care of the dying in a network of hospitals and institutions in Queensland. Intern Med J 2007;37:315-9.

12. Cummings $\mathrm{A}$, Lund $\mathrm{S}$, Campling $\mathrm{N}$, et al. Implementing communication and decision-making interventions directed at goals of care: A theory-led scoping review. BMJ Open 2017;7:e017056.

13. Mellor F, Foley T, Connolly M, et al. Role of a clinical facilitator in introducing an integrated care pathway for the care of the dying. Int J Palliat Nurs 2004;10:497-501.

14. Khan RI. End of life care in Pakistan; some ethical issues. J Coll Physicians Surg Pak 2012;22:745-6.

15. Abarshi E, Echteld M, Van den Block L, et al. Transitions between care settings at the end of life in the Netherlands: Results from a nationwide study. Palliat Med 2010;24:166-74.

16. Parish K, Glaetzer K, Grbich C, et al. Dying for attention: Palliative care in the acute setting. Aust J Adv Nurs 2006;24:21-5.

17. Lo SH, Chan CY, Chan CH, et al. The implementation of an end-of-life integrated care pathway in a Chinese population. Int J Palliat Nurs 2009;15:384-8.

18. Raijmakers N, Dekkers A, Galesloot C, et al. Barriers and facilitators to implementation of the liverpool care pathway in the Netherlands: A qualitative study. BMJ Support Palliat Care 2015;5:259-65.

19. Ellershaw J, Ward C. Care of the dying patient: The last hours or days of life. BMJ 2003;326:30-4.

20. Centeno C, Lynch T, Donea O, et al. EAPC Atlas of Palliative Care in Europe 2013. Milan: EAPC Press; 2013. 